\title{
Protective Effect of Pitao (Pitavia punctata (R. \& P.) Molina) Polyphenols against the Red Blood Cells Lipoperoxidation and the In Vitro LDL Oxidation
}

\author{
Ricardo I. Castro, ${ }^{1,2}$ Oscar Forero-Doria ${ }^{D},{ }^{3}$ Luis Soto-Cerda, ${ }^{4,5}$ \\ A. Peña-Neira, ${ }^{6}$ and Luis Guzmán ${ }^{7}{ }^{7}$ \\ ${ }^{1}$ Multidisciplinary Agroindustry Research Laboratory, Universidad Autónoma de Chile, Talca, Chile \\ ${ }^{2}$ Carrera de Ingeniería en Construcción e Instituto de Ciencias Biomédicas, Universidad Autónoma de Chile, Talca, Chile \\ ${ }^{3}$ Instituto de Química de Recursos Naturales, Universidad de Talca, Talca, Chile \\ ${ }^{4}$ Facultad de Ciencias Forestales, Universidad de Talca, Talca, Chile \\ ${ }^{5}$ Centro de Plantas Nativas de Chile (CENATIV), Universidad de Talca, Talca, Chile \\ ${ }^{6}$ Department of Agro-Industry and Enology, Faculty of Agronomical Sciences, University of Chile, P.O. Box 1004, Santiago, Chile \\ ${ }^{7}$ Departamento de Bioquímica Clínica e Inmunohematología, Facultad de Ciencias de la Salud, Universidad de Talca, Talca, Chile
}

Correspondence should be addressed to Luis Guzmán; lguzman@utalca.cl

Received 19 March 2018; Revised 17 June 2018; Accepted 28 June 2018; Published 30 July 2018

Academic Editor: Maria G. Miguel

Copyright (c) 2018 Ricardo I. Castro et al. This is an open access article distributed under the Creative Commons Attribution License, which permits unrestricted use, distribution, and reproduction in any medium, provided the original work is properly cited.

\begin{abstract}
The oxidative stress is characterized by an imbalance between the oxidizing agents and antioxidants; meanwhile, the consumption of antioxidants has been considered as an important tool in the prevention of oxidative stress and its consequences. Pitavia punctata (R. \& P.) Molina is an endemic arboreal species from the Chilean Coast Range, in which a large amount of flavonoids has been described. This work focused on characterizing and evaluating, in human erythrocytes, the antioxidant capacity and membrane protection of P. punctata extracts and the in vitro protection of the oxidation of the Low Density Lipoprotein (LDL). The phytochemical screening revealed the presence of Quercetin derivatives and flavonoids, such as (-)-Epicatechin, Kaempferol, and derivatives. The methanolic extract presented an important antioxidant activity, protecting the membrane integrity of the red blood cells against the oxidative damage caused by Hypochlorous acid and inhibiting the oxidation of the LDL lipoprotein.
\end{abstract}

\section{Introduction}

Nowadays, one of the major public-health problems is the metabolic syndrome (MS), which increases the risk of cardiovascular diseases and type II diabetes [1]. Many of the complications of the MS have been strongly associated with oxidative stress, characterized by an imbalance between the oxidizing agents (reactive oxygen species, lipid peroxidation) and antioxidants $[2,3]$.

Polyphenols have the capacity of scavenging free radicals and reactive oxygen species (ROS) $[4,5]$. On the other hand, the flavonoids inhibit the nitric oxide synthase that generates nitric oxide, which reacts with free radicals to generate peroxynitrite species $[6,7]$. The antioxidant mechanisms of phenols and flavonoids have not been yet elucidated; nevertheless, these compounds have the ability of partition in cell membranes, resulting in a restriction on the membrane fluidity, preventing the diffusion of free radicals [8].

Many natural herbs with medicinal properties have been described [9]; among them, Pitavia punctata (R. \& P.) Molina (Figure 1), an endemic arboreal species from the Chilean Coast Range in Central Chile $\left(35^{\circ} 21^{\prime} S-37^{\circ} 41^{\prime} S\right)$, belongs to a monotypic genus from Rutaceae [10], also known as "Pitao", "Canelillo", and "Pitrán" [11, 12]. In addition, a large amount of polyphenols has been described, and antioxidant activity in species of the family Rutaceae, e.g., citrus fruits, has large amounts of catechins, flavanones, and flavanonols, such as naringenin, hesperetin, liquiritin, and their glycosides [13], compounds with many antioxidant properties and low toxicities $[14,15]$. 


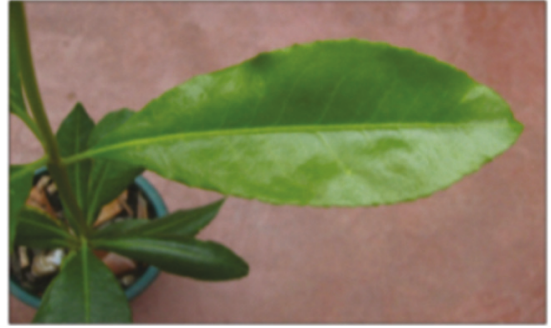

(a)

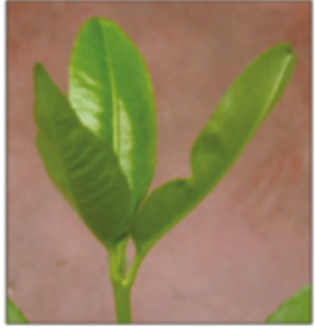

(b)

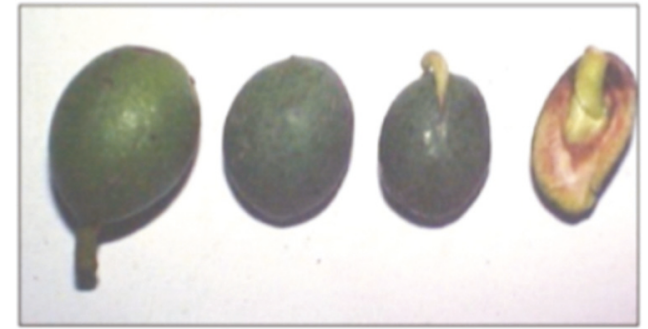

(c)

Figure 1: Pitavia punctata. (a) Leave; (b) whorled phyllotaxy; (c) fruits (photography taken from Dr. Alejandro Troncoso Aguilar records).

Given the importance of antioxidants in the prevention of the MS and its consequences, the antioxidant capacity and membrane protection of $P$. punctata extracts and the in vitro protection of the oxidation of the Low Density Lipoprotein (LDL) were evaluated in human erythrocytes.

\section{Materials and Methods}

2.1. Chemicals. Caffeic acid, (-)-Epicatechin, Quercetin, Myricetin, Kaempferol Quercetin (-)-Epicatechin-3-O-gallate (E-3893) were purchased from Sigma Chemical Co. (St Louis, MO, USA). The flavonols Quercetin glucoside, Myricetin glucoside, and flavones Apigenin glucoside were purchased from Extrasynthèse (Genay, France). Flavonols Myricetin3-O-galactoside, Myricetin-3-O-glucoside, Isorhamnetin-3O-galactoside, Quercetin-3-galactoside, Quercetin-3-glucuronide, Quercetin-3-glucoside, Quercetin-3-rhamnoside, Kaempferol-3-galactoside, and Kaempferol-3-glucoside were provided by Apin Chemicals (Abingdon, Oxford, UK). All the solvents, (HPLC) grade, acetonitrile, acetic acid, formic acid, and methanol, were purchased from Merck (Darmstadt, Germany).

\subsection{Plant Material and Extraction. Samples were collected} in Cauquenes province, in "El Avellano, El Aromo" property $\left(35^{\circ} 51^{\prime} 44^{\prime \prime} \mathrm{S}-72^{\circ} 25^{\prime} 53^{\prime \prime} \mathrm{O}\right)$. This property is located next to Cauquenes-Pelluhue M-50 route and is surrounded by commercial plantations of Pinus radiata and Eucalyptus spp. This site presents a Nothofagus glauca forest, southwest exposure, and an elevation of 407 meters above sea level. The collection date was July 25th, 2013. Pitavia punctata botanical material was taxonomically determined by Luis Soto-Cerda, who has worked during the last ten years in coastal range forest research in the region of Maule. Later, this identification was corroborated by Alicia Marticorena, M.S., curator of the University of Concepción Herbarium. All samples were dried at room temperature (between 20 and $30^{\circ} \mathrm{C}$ ) for three weeks in dark conditions. A voucher sample was stored in University of Concepción Herbarium (Voucher $\mathrm{N}^{\circ}$ 176999), under controlled ambient conditions, with the Herbarium collection.

A methanolic extract was obtained from $310 \mathrm{~g}$ of dried plant in $1 \mathrm{~L}$ of methanol and then was filtered and taken to dryness under reduced pressure; a green color residue was obtained (16.6 g). The crude methanol sample (15.9 g of $16.6 \mathrm{~g})$ was extracted successively with dichloromethane (DCM), acetone $(\mathrm{Ac})$, and methanol $(\mathrm{MeOH})$ at room temperature, respectively. The w/w yields in terms of dry starting material for the DCM, Ac, and MeOH extract were 10.0\% (1.6 g), $1.80 \%$ $(0.3 \mathrm{~g})$, and $88.2 \%(14.0 \mathrm{~g})$, respectively. All the extracts were tested for total phenols, flavonoid content, and free radical scavenging (DPPH).

2.3. Total Phenolic and Flavonoid Contents. The total phenolic contents of the extracts of Pitavia punctata were determined using the method described previously [16]. Briefly, a sample $(160 \mu \mathrm{L})$ of the different extracts was mixed with $100 \mu \mathrm{L}$ of Folin-Ciocalteu reagent and incubated 5 min before the addition of $300 \mu \mathrm{L}$ of $20 \%$ sodium carbonate $\left(\mathrm{Na}_{2} \mathrm{CO}_{3}\right)$; the reaction tubes were diluted to $1.2 \mathrm{~mL}$ with distiller water and then incubated for $1 \mathrm{~h}$. The absorbance of the mixture was read at $765 \mathrm{~nm}$ using a spectrophotometer (Thermo Spectronic GENESYS $10 \mathrm{UV}$ ) and the quantification was made on the basis of a standard curve of Gallic acid. The results were expressed as $\mathrm{mg}$ of Gallic acid equivalents (GAE) per gram of extract.

The total flavonoids contents of the extracts were determined by the methodology described previously [17]. Briefly, a sample $(200 \mu \mathrm{L})$ of the different extracts was mixed with $60 \mu \mathrm{L}$ of $5 \%$ sodium nitrite $\left(\mathrm{NaNO}_{2}\right)$; after $6 \mathrm{~min}$ of incubation, $60 \mu \mathrm{L}$ of $10 \%$ aluminium chloride $\left(\mathrm{AlCl}_{3}\right)$ was added and incubated for $6 \mathrm{~min}$ before the addition of $400 \mu \mathrm{L}$ of $4 \%$ sodium hydroxide $(\mathrm{NaOH})$. As reference, a calibration curve was made using Quercetin as a standard; the absorbance of the reaction mixture was measured at $415 \mathrm{~nm}$ and the results were expressed as mg of Quercetin equivalents $(\mathrm{QE})$ per gram of extract.

\subsection{Antioxidant Activity}

2.4.1. DPPH (1,1-Diphenyl-2-Picrylhydrazyl) Radical Scavenging Method. The assay was done according to BrandWilliams et al., 1995 [18], adapted to microwells. Briefly, $75 \mu \mathrm{L}$ of several dilutions $(1 / 2)$ of the extracts and control (80\% methanol) was mixed with $150 \mu \mathrm{L}$ of $\mathrm{DPPH}$ reagent $(20 \mathrm{mg} / \mathrm{L}$ in methanol). After $15 \mathrm{~min}$ of incubation, the absorbance was measured at $515 \mathrm{~nm}$ using a microplate reader spectrophotometer. The antioxidant activity (as percentage) was calculated as follows: 


$$
\% \text { Scavenging DPPH free radical }=100 \times\left(1-\frac{\mathrm{AS}}{\mathrm{AD}}\right)
$$

where AS is the absorbance of the extract dilution plus DPPH reagent and $\mathrm{AD}$ is the absorbance of the $\mathrm{DPPH}$ solution $(20 \mathrm{mg} / \mathrm{L})$. The half-maximal inhibitory concentration $\left(\mathrm{IC}_{50}\right.$, $\mathrm{mg} / \mathrm{mL}$ ) was calculated by linear regression analysis and expressed as mean of three determinations. Quercetin was used as reference compounds.

2.4.2. FRAP (Ferric Reducing Antioxidant Power) Assay. The FRAP reagent was prepared with $2.5 \mathrm{~mL}$ of 2,4,6-Tris (2pyridyl)-s-triazine dissolved in $40 \mathrm{mM} \mathrm{HCl}, 25 \mathrm{~mL}$ of $300 \mathrm{mM}$ of acetate buffer $\mathrm{pH} 3.6$, and $2.5 \mathrm{~mL}$ of $20 \mathrm{mM} \mathrm{FeCl}_{3}$ * $6 \mathrm{H}_{2} \mathrm{O}$ [19]. Briefly, a sample $(50 \mu \mathrm{L})$ of the different extracts or standard $\left(\mathrm{FeSO}_{4} * 7 \mathrm{H}_{2} \mathrm{O}, \mathrm{Fe}^{2+}\right.$ concentration versus absorbance) was mixed with $1.5 \mathrm{~mL}$ of FRAP solution and diluted to a final volume of $1.7 \mathrm{~mL}$ with water. The reaction tubes were incubated at room temperature for 15 minutes and the product (ferrous tripyridyltriazine complex) was read at $593 \mathrm{~nm}$, using a spectrophotometer (Thermo Spectronic GENESYS $10 \mathrm{UV}$ ). The percentage of $\mathrm{Fe}^{3+}$ scavenging (reduction to $\mathrm{Fe}^{2+}$ ) was calculated by comparison with the standard curve $\left(\mu \mathrm{mol} \mathrm{Fe}{ }^{2+}\right.$ per g of extract).

\subsection{HPLC-DAD Analysis of Low-Molecular-Weight Phenolic} Compounds. Several low-molecular-weight phenolic compounds were weighed $(1.5 \mathrm{mg})$ and dissolved in $1 \mathrm{~mL}$ of 1:1 $(\mathrm{v} / \mathrm{v})$ methanol/water and membrane-filtered $(0.45 \mu \mathrm{m}$ pore size) with an HPLC coupled to a diode array detector (Agilent ChemStation, 1200, USA), equipped with a low-pressure quaternary pump (model Agilent 1200) and autosampler (model Agilent 1260 Infinity Autosampler). The separation was made at $20^{\circ} \mathrm{C}$ using a Nova-Pak C18 column at $300 \mathrm{~mm}$ and the injection volume was $25 \mu \mathrm{L}$ of sample. All the phenols were determined by a direct readout of the sample absorbance at $280 \mathrm{~nm}$. The photodiode array detector was set from 210 to $360 \mathrm{~nm}$. Two mobile phases were used: A, water/acetic acid $(98: 2 \mathrm{v} / \mathrm{v}) ; B$, water/acetonitrile/acetic acid $(78: 20: 2 \mathrm{v} / \mathrm{v} / \mathrm{v})$, with a flow rate of $1 \mathrm{~mL} \mathrm{~min}^{-1}$ from 0 to $55 \mathrm{~min}$ and $1.2 \mathrm{~mL}$ $\mathrm{min}^{-1}$ from 55 to $85 \mathrm{~min}$ as follows: $100-20 \% \mathrm{~A}$ from 0 to $55 \mathrm{~min}, 20-10 \%$ A from 55 to $57 \mathrm{~min}$, and $10-0 \%$ A from 57 to $85 \mathrm{~min}$. Each major peak in the HPLC chromatograms was characterized by both the retention time and the absorption spectrum (from 210 to $360 \mathrm{~nm}$ ).

2.6. Membrane Integrity of the Red Blood Cells. The membrane integrity of the red blood cells (RBCs) was determined according to Suwalsky et al., 2007 [20]. Briefly, RBCs were obtained from healthy volunteers by puncturing the ear lobule (blood sample $0.1 \mathrm{~mL}$ ) in $10 \mu \mathrm{L}$ of heparin $(5000 \mathrm{UI} / \mathrm{mL})$. The RBCs were washed (three times) by adding $900 \mu \mathrm{L}$ of phosphate-buffered saline (PBS) $\mathrm{pH} 7.4$ and, after gently mixed, were centrifuged at $1000 \mathrm{rpm} \times 10 \mathrm{~min}$; the supernatant was discarded and replaced by the same volume of saline PBS pH 7.4. The washed RBCs $(2 \%, \mathrm{v} / \mathrm{v})$ were incubated with the selected extract of $P$. punctata $(10$ and $100 \mu \mathrm{g} / \mathrm{mL}$ ) for $15 \mathrm{~min}$, then Hypochlorous acid ( $\mathrm{HClO})$ was added $(25 \mu \mathrm{M}$, final volume), and the solution was incubated for $1 \mathrm{~h}$ at $37^{\circ} \mathrm{C}$, as a negative control $0.9 \%$ of sodium chloride $(\mathrm{NaCl})$. After the incubation the samples were centrifuged $(1000 \mathrm{rpm} \times$ $10 \mathrm{~min}$ ) and the supernatant was discarded. The remaining RBCs were fixated by addition of $500 \mu$ l of glutaraldehyde $(2.5 \%, \mathrm{v} / \mathrm{v})$ and examined by scanning electron microscopy.

2.7. Inhibition of RBCs Lipoperoxidation. The inhibition of the RBCs lipoperoxidation was carried out according to Yang et al., 2007 [21], with some modifications. Briefly, washed RBCs $(100 \mu \mathrm{L})$ at $50 \%$ were mixed with $20 \mu \mathrm{L}$ of different concentrations of the $\mathrm{MeOH}, \mathrm{Ac}$, and DCM extracts and $780 \mu \mathrm{L}$ of saline solution; the mixture was incubated for $10 \mathrm{~min}$ at $37^{\circ} \mathrm{C}$. Then, $100 \mu \mathrm{L}$ of $1 \mathrm{mM}$ tert-butylhydroperoxide (t-BHP) was added (under constant shaking) and, after 15 min of incubation at $37^{\circ} \mathrm{C}, 100 \mu \mathrm{L}$ of $1 \%$ Triton X-100 was added to stop the lipoperoxidation.

The lipoperoxidation process was measured by the thiobarbituric acid reactive substances (TBARS) assay. Briefly, $2 \mathrm{~mL}$ of thiobarbituric acid/trichloroacetic acid/hydrochloric acid (TBA/TCA/HCl) was added to reaction tubes along with the samples. The mixture was centrifuged at $3500 \mathrm{rpm}$ for $5 \mathrm{~min}$ and the supernatant $(2 \mathrm{~mL})$ was boiled at $90^{\circ} \mathrm{C}$ for $15 \mathrm{~min}$. The absorbance was read at $535 \mathrm{~nm}$ in a spectrophotometer (Thermo Spectronic GENESYS $10 \mathrm{UV}$ ). The halfmaximal inhibitory concentration $\left(\mathrm{IC}_{50}, \mu \mathrm{g} / \mathrm{mL}\right.$ ) was calculated by linear regression analysis and expressed as mean of three determinations; as reference, a calibration curve was made using Malondialdehyde as a standard.

2.8. Isolation and Oxidation of Low Density Lipoprotein (LDL). LDL isolated from plasma of healthy volunteers was obtained by differential centrifugation as described previously [22]. The isolated LDL (dialyzed with $\mathrm{Ca}^{+2}-\mathrm{Mg}^{+2}$-free PBS) was stored in dark at $4^{\circ} \mathrm{C}$ and the oxidation was prevented adding $45 \mathrm{mM} \mathrm{BHT}$ and $2 \mathrm{mM}$ EDTA.

The production of conjugated dienes (LDL oxidation) was followed at $243 \mathrm{~nm}$. For the oxidation, $50 \mu \mathrm{g} / \mathrm{mL}$ of native LDL was mixed with cooper $\left(5 \mu \mathrm{M}\right.$ of $\left.\mathrm{CuSO}_{4}\right)$ in the absence (control) or presence of the extract ( 5 and $10 \mu \mathrm{g} / \mathrm{ml}$ ) dissolved in $0.9 \% \mathrm{NaCl}$; the generation of conjugated dienes was followed for $6 \mathrm{~h}$, in a controlled temperature $\left(37^{\circ} \mathrm{C}\right)$. The lag time was determined using the software GEN 5Oे by Biotek instruments. The results were expressed as means \pm standard error $(n=6)$ and ascorbic acid $(0.5 \mu \mathrm{M})$ was used as a reference antioxidant.

2.9. Statistical Analysis. The results were expressed as means \pm standard deviation of triplicate analyses. Data were statistically analyzed using the SPSS statistical software, version 15 (SPSS Inc., Chicago, IL). ANOVA test was used for comparison of means between groups with a level of significance of $p<0.05$.

\section{Results and Discussion}

3.1. Phenol and Flavonoid Content. The concentrations of phenols obtained from the different extract were $130.8 \pm$ $6.2(\mathrm{DCM}), 56.8 \pm 1.3(\mathrm{Ac})$, and $170.3 \pm 8.6(\mathrm{MeOH}) \mathrm{mg}$ 
TABLE 1: Total phenolic and flavonoid contents and antioxidant activity of the different extracts obtained from P. punctata.

\begin{tabular}{lccc}
\hline Measurement & $\begin{array}{c}\text { Methanol } \\
(\mathrm{MeOH})\end{array}$ & $\begin{array}{c}\text { Acetone } \\
(\mathrm{Ac})\end{array}$ & $\begin{array}{c}\text { Dichloromethane } \\
(\mathrm{DCM})\end{array}$ \\
\hline $\begin{array}{l}\text { Total Phenols } \\
(\mathrm{mg} \text { GAE/g of extract) }\end{array}$ & $170.3 \pm 8.6$ & $56.8 \pm 1.3$ & $130.8 \pm 6.2$ \\
$\begin{array}{l}\text { Total Flavonoid } \\
(\mathrm{mg} \mathrm{QE} / \mathrm{g} \text { of extract) }\end{array}$ & $137.5 \pm 5.9$ & $17.6 \pm 3.6$ & $111.6 \pm 1.2$ \\
$\left.\begin{array}{l}\mathrm{DPPH} \\
(\mathrm{IC}\end{array}\right)(\mathrm{mg} / \mathrm{mL})$ & $0.07 \pm 0.002$ & $>0.1$ & $0.098 \pm 0.002$ \\
$\begin{array}{l}\text { FRAP } \\
(\mu \mathrm{mol} \mathrm{Fe} / \mathrm{g} \text { of extract })\end{array}$ & $851.9 \pm 7.4$ & $185.2 \pm 5.4$ & $548.2 \pm 6.2$ \\
\hline
\end{tabular}

DPPH: 1,1-diphenyl-2-picrylhydrazyl; FRAP: ferric reducing antioxidant power. ${ }^{* *} p<0.0018$ among them; ${ }^{* * *} p<0.0001$ among them.

GAE/g of extract, and for flavonoids they were $111.6 \pm 1.2$ (DCM), $17.6 \pm 3.6(\mathrm{Ac})$, and $137.5 \pm 5.9(\mathrm{MeOH}) \mathrm{mg} \mathrm{QE} / \mathrm{g}$ of extract. The phenolic and flavonoid content of these extracts diminished in a decreasing polarity order: $\mathrm{MeOH}>\mathrm{DCM}>$ Ac, demonstrating a major concentration of both metabolites in the $\mathrm{MeOH}$ extract (Table 1).

3.2. Antioxidant Capacity of the P. punctata Extracts. The antioxidant capacity of the different extracts of $P$. punctata was tested by the free radical scavenging assay (DPPH); the results showed $\mathrm{IC}_{50}(\mathrm{mg} / \mathrm{mL})$ values of $>0.1$ (Ac), 0.098 $\pm 0.002(\mathrm{DCM})$, and $0.07 \pm 0.002(\mathrm{MeOH})$. The radical scavenging effects of these extracts decreased in the polarity: $\mathrm{MeOH}>\mathrm{DCM}>\mathrm{Ac}$, demonstrating that the most active extract was the $\mathrm{MeOH}$ extract (Table 1). For its part, the methanolic extract showed the higher capacity to reduce the $\mathrm{Fe}^{3+}$ to $\mathrm{Fe}^{2+}$ with $851.9 \pm 7.4 \mu \mathrm{mol} \mathrm{Fe}{ }^{2+} / \mathrm{g}$ of extract, followed by the dichloromethane extract $\left(548.2 \pm 14.8 \mu \mathrm{mol} \mathrm{Fe}{ }^{2+} / \mathrm{g}\right.$ of extract) and the acetone extract $\left(185.2 \pm 7.4 \mu \mathrm{mol} \mathrm{Fe}{ }^{2+} / \mathrm{g}\right.$ of extract).

The results show a correlation between the flavonoid and phenolic content with the antioxidant activity. The presence of organic acids and polyphenols has demonstrated multiple biological properties in vitro and in vivo including antioxidant activities, among the phenolic antioxidants, with the flavonoid family being the most important class [23].

There is only one report about phytochemical study to the endemic Chilean specie P. punctata belonging to the Pitavia genus. In this report Silva et al., 1971 [24], isolated and characterized from leaves different secondary metabolites such as the furoquinoline alkaloids dictamnine, skimmianine and $\gamma$ fagarine in $0.004 \%, 0.0005 \%$, and small quantities, respectively, based on dry plant weight. In addition different furoquinoline alkaloids have also been isolated from other members of the Rutaceae family. Thus, Rosas et al., 2011 [25], reported the presence of the furoquinolines maculosidine, robustine, and evolitrine among others, from the Raputia praetermissa species. Also, from the Zanthoxylum buesgenii species, three known furoquinolines have been reported: maculine, kokusaginine, and teclearverdoornine [26]. Likewise, from the Helietta apiculata [27] and Sarcomelicope follicularis [28] species, the presence of these alkaloids has been reported. On the other hand, from the benzene extract derived from leaves of $P$. punctata the common sterols $\beta$ sitosterol and daucosterin have been isolated, and in the methanolic extract Quercetin and avicularin, among other flavonols, were reported.

Different reports of the presence of different phenolic compounds in species belonging to the Rutaceae family could be found. At this respect, the specie Skimmia anquetilia ( $R u$ taceae) has shown a total phenolic concentration of $1.1 \mathrm{mg} / \mathrm{g}$ of aqueous extract of oil obtained from the leaf with a good correlation among the phenolic content and the antioxidant activity [29]; for its part, a better antioxidant capacity (DPPH) was found in a bark extract of Melicope glabra with an $\mathrm{IC}_{50}$ of $13.01 \pm 0.01 \mu \mathrm{g} / \mathrm{mL}$; also, a Pearson's correlation between the total phenolic content and the antioxidant activity (DPPH), using various concentrations, was calculated in 0.620 , being statistically significant $(p<0.01)[30]$.

3.3. HPLC-DAD Analysis of Low-Molecular-Weight Phenolic Compounds. The phenolic compounds identification from the $\mathrm{MeOH}$ extract of $P$. punctata was carried out by comparing the retention time and its absorption spectrum with those of the standard curve; in order to assign the identity of the peaks, each peak was labeled with a number according to its elution order in the chromatogram (Figure 2).

The phenolic compounds found in the $\mathrm{MeOH}$ extract include Quercetin derivates, previously described in $P$. punctata [24]; also, Quercetin derivates such as Quercetin3-galactoside, Quercetin-3-glucuronide, and Quercetin-3glucoside, were identified; additionally, other flavonoids such as (-)-Epicatechin, (-)-Epicatechin-3-O-gallate, Kaempferol, and derivates were identified; finally, phenols such as caffeic acid were identified (Table 2 ).

The presence of different phenolic compounds in the $\mathrm{MeOH}$ extract such as (-)-Epicatechin and its derivative ()-Epicatechin-3-O-gallate and Quercetin derivates are some of the responsible for the antioxidant capacity of this extract, mainly for the characteristic presence of hydroxyl groups in the structure of these compounds that can donate hydrogen atoms in order to disrupt the chain propagation reaction of the oxidative process [31, 32]; moreover, neurological, antiviral, anticancer, cardiovascular, antimicrobial, and antiinflammatory activities have been reported [33, 34]. The presence of Kaempferol flavonoid and its derivatives and the 


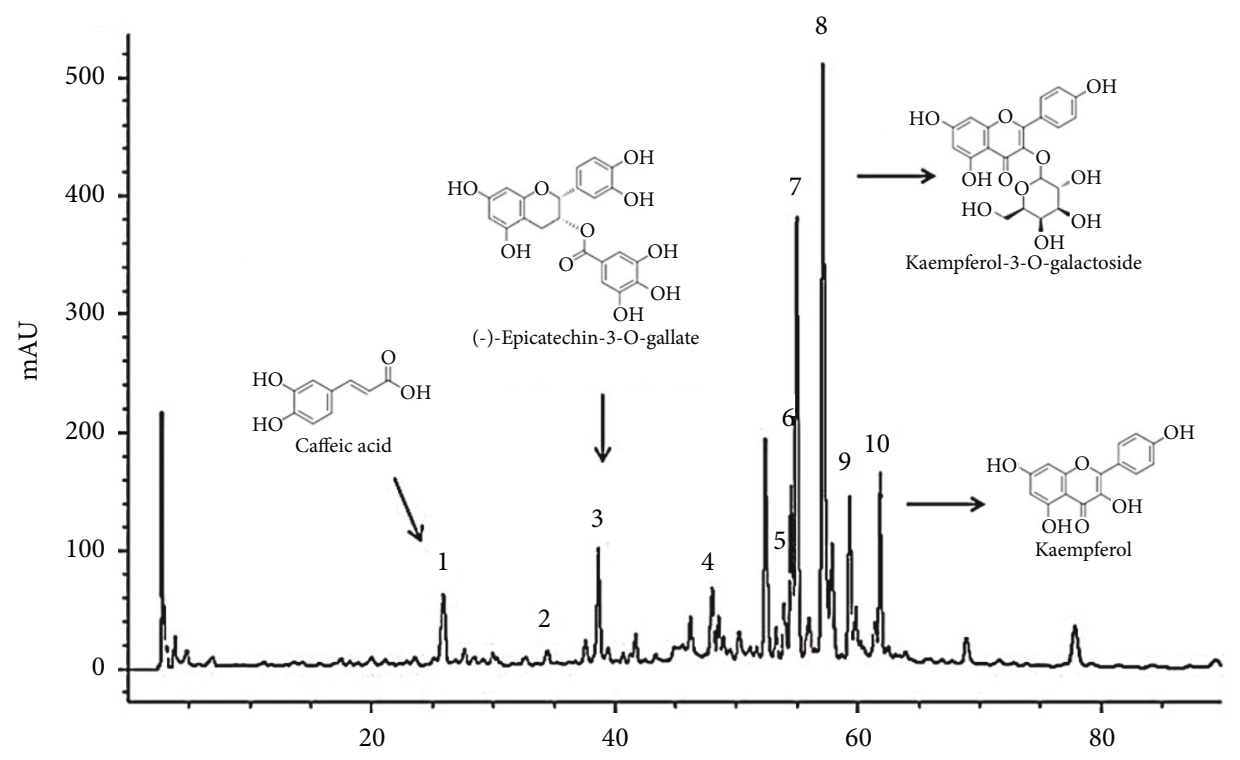

Figure 2: HPLC-DAD chromatograms of the $\mathrm{MeOH}$ extract of Pitavia punctata, detected at $280 \mathrm{~nm}$. Peak numbers refer to Table 2.

TABLE 2: Tentative identification of phenolic compounds in the MeOH extract from leaves of Pitavia punctata by HPLC-DAD.

\begin{tabular}{lcccc}
\hline Peak \# & Rt $(\mathbf{m i n})$ & $\lambda \mathbf{m a x}(\mathbf{n m})$ & MW & Tentative identification \\
\hline 1 & 25.8 & $280^{\mathrm{s}}, 323,300^{\mathbf{s}}$ & 178 & Caffeic acid \\
2 & 34.4 & 280,235 & 290 & $(-)$-Epicatechin \\
3 & 38.6 & 280 & 442 & $(-)$-Epicatechin-3-O-gallate \\
4 & 47.9 & 270,340 & - & Unknown \\
5 & 53.9 & $280^{\mathrm{s}}, 354,300^{\mathrm{s}}, 256$ & 464 & Quercetin-3-galactoside \\
6 & 54.4 & $280^{\mathrm{s}}, 354,300^{\mathrm{s}}, 256$ & 478 & Quercetin-3-glucuronide \\
7 & 55.9 & $280^{\mathrm{s}}, 354,300^{\mathrm{s}}, 256$ & 464 & Quercetin-3-glucoside \\
8 & 57.1 & 280,348 & 448 & Kaempferol-3-O-galactoside \\
9 & 59.2 & 354,256 & 286 & Unknown \\
10 & 61.8 & $280^{\mathrm{s}}, 346,256$, & Kaempferol \\
\hline
\end{tabular}

${ }^{s}$ Shoulder

presence of caffeic acid (hydroxycinnamic acid) contribute to the antioxidant capacity thanks to its antioxidant power [35].

\subsection{Morphology and Inhibition of RBCs Lipoperoxidation.} The morphology and membrane structure of the RBCs were studied by scanning electron microscope (SEM). After exposure of $25 \mu \mathrm{M}$ of $\mathrm{HClO}$, the RBCs lose their normal shape showing changes in the morphology of the RBCs, mainly in the form of echinocytes (Figure 3(b)). The RBCs incubated with $10 \mu \mathrm{g} / \mathrm{mL}$ of the methanolic extract of P. punctata and subjected to the oxidant agent $\mathrm{HClO} 25 \mu \mathrm{M}$ showed less changes compared with the positive control ( $\mathrm{HClO} 25 \mu \mathrm{M})$; meanwhile, the highest concentration used $(100 \mu \mathrm{g} / \mathrm{mL})$ showed almost no changes in the morphology of the RBCs (Figure 3(d)), maintaining their biconcave discoid shape, demonstrating a membrane protection in a concentration dependent manner of the methanolic extract of $P$. punctata.

The lipoperoxidation analysis showed that the $\mathrm{MeOH}$ extract was the most effective, protecting the membrane of RBCs peroxidation with an $\mathrm{IC}_{50}$ of $13.6 \pm 1.7 \mu \mathrm{g} / \mathrm{mL}$
(Figure 4); the DCM extract showed poor protection against the lipoperoxidation with an $\mathrm{IC}_{50}$ of $63 \pm 2.3 \mu \mathrm{g} / \mathrm{mL}$ and the Ac extract showed no effect at the higher concentration used $\left(\mathrm{IC}_{50}>100 \mu \mathrm{g} / \mathrm{mL}\right)$.

The peroxidation of lipids has been accepted as one of the primary events in the oxidative cellular damage; at the same time, the RBCs are very susceptible to oxidation by various agents such as hydrogen peroxide, xanthine oxidase, dialuric acid, and organic hydroperoxides, inducing haemolysis and membrane damage [36].

The results showed that the $\mathrm{MeOH}$ extract of Pitavia punctata reduced the red blood cell damage induced by $\mathrm{HOCl}$, in a concentration dependent manner; also, the $\mathrm{MeOH}$ extract was the most effective inhibiting the induced oxidation of lipids in the RBCs. In vivo, the strong oxidant $\mathrm{HOCl}$ is generated in substantial amounts via the myeloperoxidasecatalyzed oxidation of chloride by hydrogen peroxide [37, 38], and it has been demonstrated that the treatment of RBCs with $\mathrm{HClO}$ results in an inhibition of the $\mathrm{Na}^{+}, \mathrm{K}^{+}$, and $\mathrm{Mg}^{2+}$ ATPase activities; also, important oxidation of $\mathrm{SH}$ - groups, 


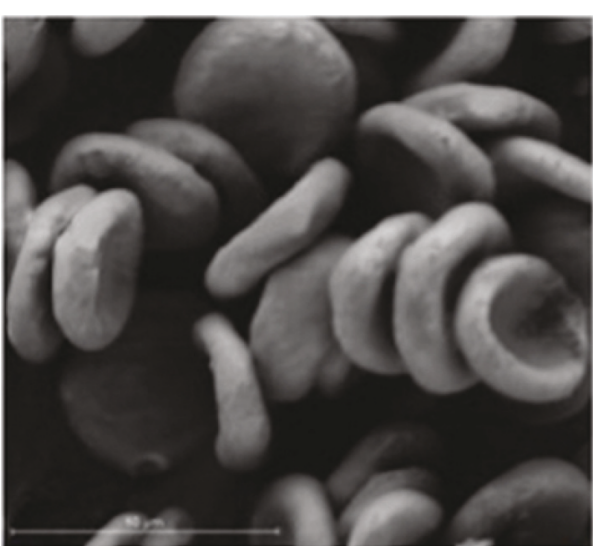

(a)

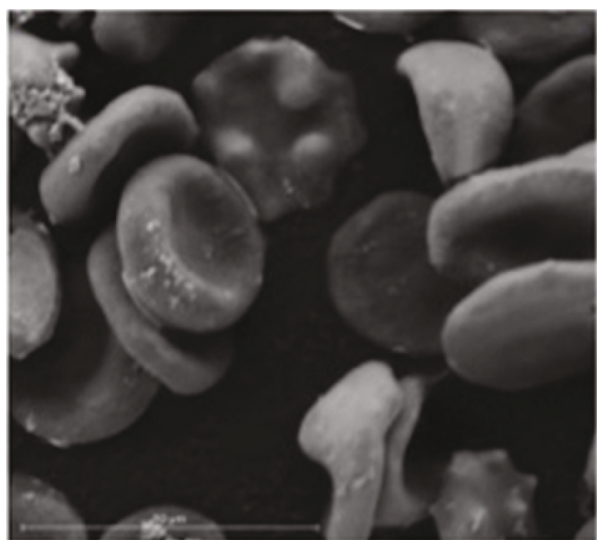

(c)

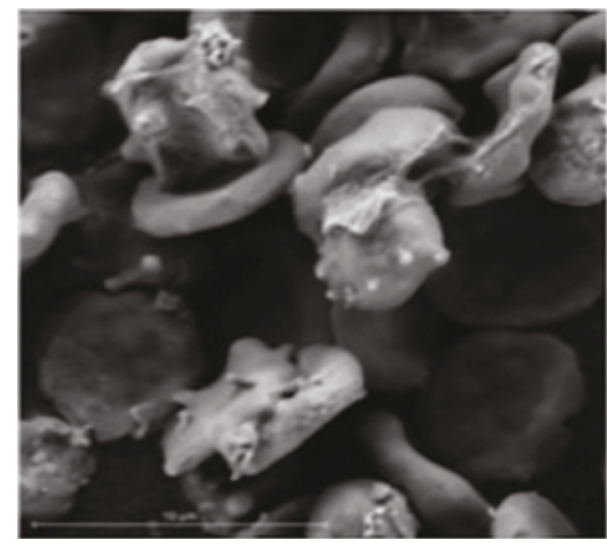

(b)

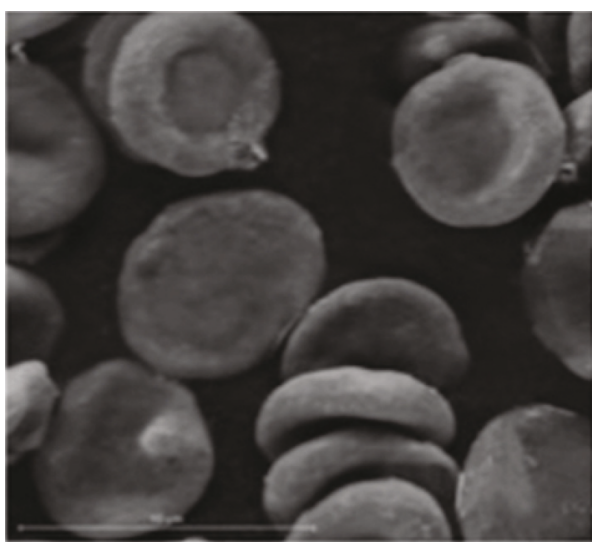

(d)

FIgURE 3: Morphology and membrane protection of RBCs by the $\mathrm{MeOH}$ extract of $P$. punctata. (a) Negative control (saline); (b) positive control $\mathrm{HClO}(25 \mu \mathrm{M})$; (c) $10 \mu \mathrm{g} / \mathrm{mL}$ of extract $+\mathrm{HClO}(25 \mu \mathrm{M})$; (d) $100 \mu \mathrm{g} / \mathrm{mL}$ of extract $+\mathrm{HClO}(25 \mu \mathrm{M})$.

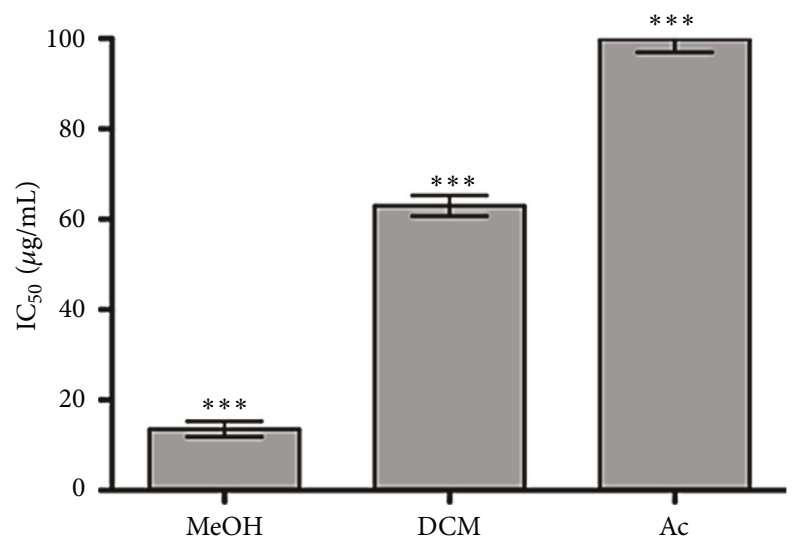

FIgURE 4: Inhibition of the lipoperoxidation $\left(\mathrm{IC}_{50}\right)$ by the $\mathrm{MeOH}$, DCM, and Ac extracts, induced by t-BHP. ${ }^{* * *} p<0.001$ among them.

with changes in the membrane fluidity, surface area, and membrane morphological transformations that precede cell lysis, has been described $[39,40]$, thereby not only enabling a protective mechanism against the oxidation consequences but also preventing the endothelial dysfunction caused by potent oxidants such as $\mathrm{HOCl}$, providing a vascular protection $[41,42]$. In turn, it has been shown that polyphenols can not only act directly on the oxidizing agents, but also act in the lipophilic environment of the lipid bilayer. In this regard, Battino et al., 2012 [43], analyzed the phenolic extracts from two monofloral Cuban honeys for their total in vitro antioxidant capacity; their results showed the ability of the polyphenols to inhibit the oxidative damage and that this is likely to be due to their incorporation into cell membranes and their ability to cross it and reach the cytosol, confirmed by testing Quercetin (one of the most abundant flavonoids found in $P$. punctata), efficiently incorporated into erythrocytes.

3.5. Effect of the MeOH Extract of Pitavia punctata on $\mathrm{Cu}^{2+}$ Induced Human LDL Oxidation. The LDL incubated for 360 min with $\mathrm{Cu}^{2+}(5 \mu \mathrm{M})$ was oxidized faster than the native LDL, with a lag time for the $\mathrm{Cu}^{2+}$-induced LDL oxidation of $78 \pm 2.3 \mathrm{~min}$; for its part, a concentration of $5 \mu \mathrm{g} / \mathrm{mL}$ of the $\mathrm{MeOH}$ extract showed no statistically significant differences against the $\mathrm{Cu}^{2+}$-induced LDL oxidation $(p>$ $0.05)$; nevertheless, a concentration of $10 \mu \mathrm{g} / \mathrm{mL}$ of the $\mathrm{MeOH}$ extract showed a significant protection against the $\mathrm{Cu}^{2+}$ oxidation (Figure 5(a)); with a lag time of $271 \pm 1.1 \mathrm{~min}$ 


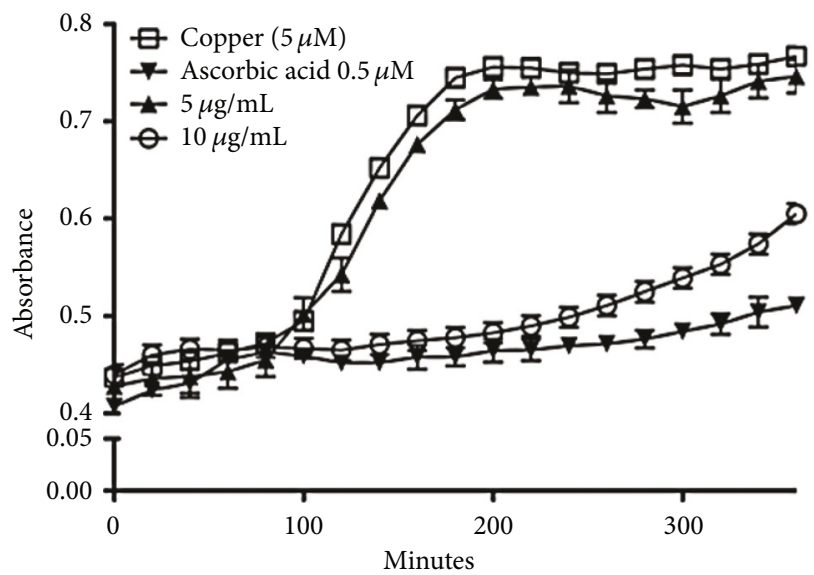

(a)

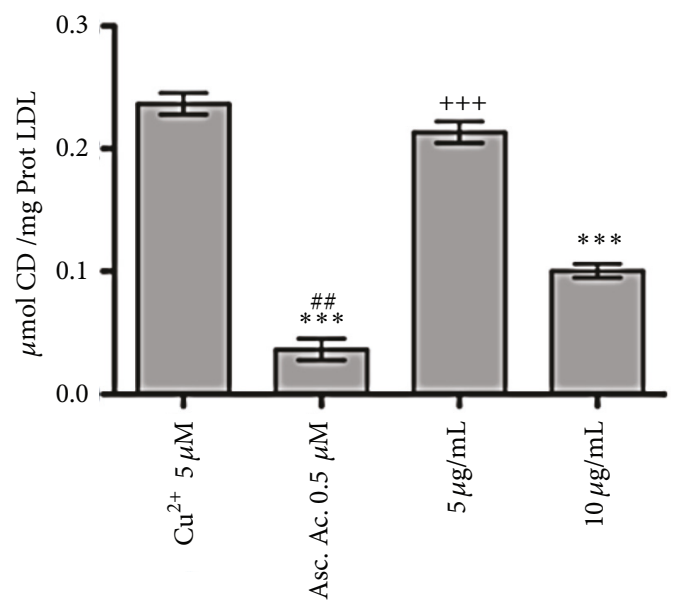

(b)

FIGURE 5: Effect of the MeOH extract of P. punctata on LDL oxidation. (a) Absorbance at $234 \mathrm{~nm}$ was measured every 2 min for 360 min at $37^{\circ} \mathrm{C}$ in a spectrophotometer to obtain a typical conjugated diene-formation (CD) curve. From the CD-formation curve, the lag time defined as end of the cross point of the time axis and the curve slope was estimated. (b) Conjugated dienes production at the final process of LDL oxidation. ${ }^{\# \#} p<0.001$ with respect to $10 \mu \mathrm{g} / \mathrm{mL}$ (MeOH extract); ${ }^{* * *} p<0.0001$ with respect to $\mathrm{Cu}^{2+} ;{ }^{+++} p<0.0001$ with respect to Asc. Ac. $0.5 \mu \mathrm{M}$ and $10 \mu \mathrm{g} / \mathrm{mL}$ (MeOH extract).

$(p<0.001)$, the ascorbic acid $0.5 \mu \mathrm{M}$ completely inhibited the $\mathrm{Cu}^{2+}$-induced LDL oxidation. The quantification of the dienes produced at the end of the oxidation process showed a total amount of $0.238 \mu \mathrm{mol} \mathrm{CD} / \mathrm{mg}$ prot-LDL $\left(\mathrm{Cu}^{2+}, 5 \mu \mathrm{M}\right)$, which was not different from the concentration of $5 \mu \mathrm{g} / \mathrm{mL}$ of the $\mathrm{MeOH}$ extract $(p>0.05)$, but a concentration of $10 \mu \mathrm{g} / \mathrm{mL}$ of the $\mathrm{MeOH}$ extract showed a reduction of $57.5 \%$ $(0.101 \mu \mathrm{mol} \mathrm{CD} / \mathrm{mg}$ prot-LDL) in the CD formation induced by $\mathrm{Cu}^{2+}$ (Figure 5(b)), showing positive protection against the oxidation of this atherogenic lipoprotein.

The oxidative modification of the LDL is an independent risk factor for cardiovascular disease, playing an important role in the pathogenesis of atherosclerosis [44]. At a subendothelial level, the LDL suffers oxidation of their polyunsaturated fatty acid component due to the increased concentration of reactive oxygen species; these oxLDL particles promote the accumulation of lipid-laden foam cells in the intima with the further impairment of the endothelial function [45].
The inhibition of the LDL oxidation due to the antioxidant capacity of the $\mathrm{MeOH}$ extract of $P$. punctata could prevent the foam cells formation (accumulation of oxidized lipid within macrophages), which in turn could prevent the atherosclerotic process [46]; the HPLC-DAD chromatograms of the $\mathrm{MeOH}$ extract of Pitavia punctata showed that the main components of the polyphenols were Quercetin and Kaempferol. Quercetin has been extensively studied as a protective agent of the vascular health, showing important effects against the oxidation of LDL with hypocholesterolemic action $[47,48]$; meanwhile, Kaempferol was the most abundant flavonoid in the $\mathrm{MeOH}$ extract; different studies have demonstrated the beneficial effect of this flavonoid on metabolic syndrome symptoms such as dyslipidemia [49, 50]; along with this, other studies have found a positive correlation between the consumption of Kaempferol or foods with an important content of Kaempferol with a reduced risk of type II diabetes and cardiovascular disease $[51,52]$. 


\section{Conclusion}

Since the role of free radicals has been implicated in a large number of diseases, the antioxidant activity of different plants has a significant importance in exploiting their therapeutic potential. The present study showed the antioxidant property of different extracts of Pitavia punctata; among them, the $\mathrm{MeOH}$ extract shows the higher content of phenolic compounds and the best protective effect against the lipoperoxidation damage caused by $\mathrm{HClO}$ to the morphology and membrane structure of human erythrocytes, and it was also found to be an effective protection against the oxidation of an atherogenic lipoprotein as the LDL. In summary, the knowledge of the antioxidant potential present in natural renewable sources such as plants makes them a source of chemical diversity with high potential for treating various diseases caused by oxidative stress.

\section{Data Availability}

The data used to support the findings of this study are included within the article.

\section{Conflicts of Interest}

The authors declare no conflicts of interest.

\section{Authors' Contributions}

Ricardo I. Castro and Luis Guzmán conceived and designed the experiments and wrote the first draft of the manuscript. Luis Soto-Cerda and A. Peña-Neira supervised the study and reviewed the manuscript. All authors analyzed and interpreted data, drafted the paper, and read and approved the final manuscript.

\section{References}

[1] K. G. Alberti, R. H. Eckel, S. M. Grundy et al., "Harmonizing the metabolic syndrome: a joint interim statement of the international diabetes federation task force on epidemiology and prevention; National heart, lung, and blood institute; American heart association; World heart federation; International atherosclerosis society; and international association for the study of obesity," Circulation, vol. 120, no. 16, pp. 1640-1645, 2009.

[2] E. S. Ford, A. H. Mokdad, W. H. Giles, and D. W. Brown, "The metabolic syndrome and antioxidant concentrations: findings from the third national health and nutrition examination survey," Diabetes, vol. 52, no. 9, pp. 2346-2352, 2003.

[3] N. Demircan, A. Gurel, F. Armutcu, M. Unalacak, E. Aktunc, and H. Atmaca, "The evaluation of serum cystatin C, malondialdehyde, and total antioxidant status in patients with metabolic syndrome," Medical Science Monitor, vol. 14, no. 2, pp. CR97CR101, 2008.

[4] P. A. Grace, "Ischaemia-reperfusion injury," British Journal of Surgery, vol. 81, no. 5, pp. 637-647, 1994.

[5] H. de Groot, "Reactive oxygen species in tissue injury," HepatoGastroenterology, vol. 41, no. 4, pp. 328-332, 1994.
[6] D. A. Shoskes, "Effect of bioflavonoids quercetin and curcumin on ischemic renal injury: A new class of renoprotective agents," Transplantation, vol. 66, no. 2, pp. 147-152, 1998.

[7] Z. Shutenko, Y. Henry, E. Pinard et al., "Influence of the antioxidant quercetin in vivo on the level of nitric oxide determined by electron paramagnetic resonance in rat brain during global ischemia and reperfusion," Biochemical Pharmacology, vol. 57, no. 2, pp. 199-208, 1999.

[8] A. Arora, T. M. Byrem, M. G. Nair, and G. M. Strasburg, "Modulation of liposomal membrane fluidity by flavonoids and isoflavonoids," Archives of Biochemistry and Biophysics, vol. 373, no. 1, pp. 102-109, 2000.

[9] D. Krishnaiah, R. Sarbatly, and R. Nithyanandam, "A review of the antioxidant potential of medicinal plant species," Food and Bioproducts Processing, vol. 89, no. 3, pp. 217-233, 2011.

[10] C. Villagrán and J. Armesto, "Fitogeografía histórica de la Cordillera de la Costa de Chile," 2005, http://www.repositorio .uchile.cl/handle/2250/120075.

[11] E. W. de Möesbach, Botánica Indígena de Chile, Editorial Andres Bello, 1992.

[12] P. Riedemann and G. Aldunate, Flora nativa de valor ornamental. Chile, Zona Sur y Austral: Identificación y propagación, Editorial Roberto Mandiola, 2nd edition, 2011.

[13] Y. Cai, Q. Luo, M. Sun, and H. Corke, "Antioxidant activity and phenolic compounds of 112 traditional Chinese medicinal plants associated with anticancer," Life Sciences, vol. 74, no. 17, pp. 2157-2184, 2004.

[14] A. Ghasemzadeh and N. Ghasemzadeh, "Flavonoids and phenolic acids: role and biochemical activity in plants and human," Journal of Medicinal Plant Research, vol. 5, no. 31, pp. 6697-6703, 2011.

[15] N. Saeed, M. R. Khan, and M. Shabbir, "Antioxidant activity, total phenolic and total flavonoid contents of whole plant extracts Torilis leptophylla L," BMC Complementary and Alternative Medicine, vol. 12, no. 1, article 221, 2012.

[16] V. L. Singleton, R. Orthofer, and R. M. Lamuela-Raventós, "Analysis of total phenols and other oxidation substrates and antioxidants by means of folin-ciocalteu reagent," Methods in Enzymology, vol. 299, pp. 152-178, 1999.

[17] C. Chang, M. Yang, H. Wen, and J. Chern, "Estimation of total flavonoid content in propolis by two complementary colorimetric methods," Journal of Food and Drug Analysis, vol. 10, no. 3, pp. 178-182, 2002.

[18] W. Brand-Williams, M. E. Cuvelier, and C. Berset, "Use of a free radical method to evaluate antioxidant activity," $L W T$-Food Science and Technology, vol. 28, no. 1, pp. 25-30, 1995.

[19] I. F. F. Benzie and J. J. Strain, "The ferric reducing ability of plasma (FRAP) as a measure of 'antioxidant power': the FRAP assay," Analytical Biochemistry, vol. 239, no. 1, pp. 70-76, 1996.

[20] M. Suwalsky, P. Orellana, M. Avello, and F. Villena, "Protective effect of Ugni molinae Turcz against oxidative damage of human erythrocytes," Food and Chemical Toxicology, vol. 45, no. 1, pp. 130-135, 2007.

[21] Y.-M. Wang, S.-Q. Peng, Q. Zhou et al., “The oxidative damage of butenolide to isolated erythrocyte membranes," Toxicology in Vitro, vol. 21, no. 5, pp. 863-869, 2007.

[22] J. Campos, G. Schmeda-Hirschmann, E. Leiva et al., "Lemon grass (Cymbopogon citratus (D.C) Stapf) polyphenols protect human umbilical vein endothelial cell (HUVECs) from oxidative damage induced by high glucose, hydrogen peroxide and oxidised low-density lipoprotein," Food Chemistry, vol. 151, pp. 175-181, 2014. 
[23] P. Cos, M. Calomme, L. Pieters, A. J. Vlietinck, D. V. Berghe, and R. Atta ur, "Structure-activity relationship of flavonoids as antioxidant and pro-oxidant compounds," in Studies in Natural Products Chemistry, pp. 307-341, Elsevier, 2000.

[24] M. Silva, M. A. Cruz, and P. G. Sammes, "Some constituents of Pitavia punctata," Phytochemistry, vol. 10, no. 12, pp. 3255-3258, 1971.

[25] L. V. Rosas, T. A. M. Veiga, J. B. Fernandes, P. C. Vieira, and M. F. Silva, "Prenylindole alkaloids from Raputia praetermissa ( $\mathrm{Ru}-$ taceae) and their chemosystematic significance," Journal of the Brazilian Chemical Society, vol. 22, no. 7, pp. 1346-1353, 2011.

[26] L. P. Sandjo, V. Kuete, R. S. Tchangna, T. Efferth, and B. T. Ngadjui, "Cytotoxic benzophenanthridine and furoquinoline alkaloids from Zanthoxylum buesgenii (Rutaceae)," Cardiovascular Intervention and Therapeutics, vol. 8, no. 1, article 61, 2014.

[27] M. E. Ferreira, A. R. de Arias, G. Yaluff et al., "Antileishmanial activity of furoquinolines and coumarins from Helietta apiculata," Phytomedicine, vol. 17, no. 5, pp. 375-378, 2010.

[28] E. Chosson, C. Guguen-Guillouzo, D. Glaise, L. Picot, E. Seguin, and T. Besson, "Cytotoxic evaluation of sarcodifurines A and B, two novel dihydrofuroquinolines from Sarcomelicope follicularis (Rutaceae)," Journal of Enzyme Inhibition and Medicinal Chemistry, vol. 23, no. 5, pp. 704-707, 2008.

[29] M. Gondwal, O. Prakash, Vivekanand, A. K. Pant, R. C. Padalia, and C. S. Mathela, "Essential oil composition and antioxidant activity of leaves and flowers of Skimmia anquetilia N.P. Taylor \& Airy Shaw," Journal of Essential Oil Research, vol. 24, no. 1, pp. 83-90, 2012.

[30] N. K. Kassim, M. Rahmani, A. Ismail et al., "Antioxidant activity-guided separation of coumarins and lignan from Melicope glabra (Rutaceae)," Food Chemistry, vol. 139, no. 1-4, pp. 87-92, 2013.

[31] L. Chen, X. Xin, Q. Yuan, D. Su, and W. Liu, "Phytochemical properties and antioxidant capacities of various colored berries," Journal of the Science of Food and Agriculture, vol. 94, no. 2, pp. 180-188, 2014.

[32] H.-S. Kim, M. J. Quon, and J.-A. Kim, "New insights into the mechanisms of polyphenols beyond antioxidant properties; lessons from the green tea polyphenol, epigallocatechin 3gallate," Redox Biology, vol. 2, pp. 187-195, 2014.

[33] A. Basu, K. Sanchez, M. J. Leyva et al., "Green tea supplementation affects body weight, lipids, and lipid peroxidation in obese subjects with metabolic syndrome," Journal of the American College of Nutrition, vol. 29, no. 1, pp. 31-40, 2010.

[34] A. Maalik, F. A. Khan, A. Mumtaz et al., "Pharmacological applications of quercetin and its derivatives: A short review," Tropical Journal of Pharmaceutical Research, vol. 13, no. 9, pp. 1561-1566, 2014.

[35] M. A. Soobrattee, V. S. Neergheen, A. Luximon-Ramma, O. I. Aruoma, and T. Bahorun, "Phenolics as potential antioxidant therapeutic agents: mechanism and actions," Mutation Research, vol. 579, no. 1-2, pp. 200-213, 2005.

[36] B. Pekiner and J. F. Pennock, "In vitro effects of an azo compound on the haemolysis and unsaturated fatty acids of red blood cells," Clinica Chimica Acta, vol. 263, no. 2, pp. 157-164, 1997.

[37] S. J. Klebanoff, "Oxygen metabolism and the toxic properties of phagocytes," Annals of Internal Medicine, vol. 93, no. 3, pp. 480489, 1980.

[38] J. M. Robinson, "Reactive oxygen species in phagocytic leukocytes," Histochemistry and Cell Biology, vol. 130, no. 2, pp. 281297, 2008.
[39] I. B. Zavodnik, E. A. Lapshina, L. B. Zavodnik, G. Bartosz, M. Soszynski, and M. Bryszewska, "Hypochlorous acid damages erythrocyte membrane proteins and alters lipid bilayer structure and fluidity," Free Radical Biology \& Medicine, vol. 30, no. 4, pp. 363-369, 2001.

[40] M. C. M. Vissers, A. C. Carr, and A. L. P. Chapman, "Comparison of human red cell lysis by hypochlorous and hypobromous acids: insights into the mechanism of lysis," Biochemical Journal, vol. 330, no. 1, pp. 131-138, 1998.

[41] R. Jiang, J. M. Hodgson, E. Mas, K. D. Croft, and N. C. Ward, "Chlorogenic acid improves ex vivo vessel function and protects endothelial cells against $\mathrm{HOCl}$-induced oxidative damage, via increased production of nitric oxide and induction of Hmox-1," The Journal of Nutritional Biochemistry, vol. 27, pp. 53-60, 2016.

[42] R. Stocker, A. Huang, E. Jeranian et al., "Hypochlorous acid impairs endothelium-derived nitric oxide bioactivity through a superoxide-dependent mechanism," Arteriosclerosis, Thrombosis, and Vascular Biology, vol. 24, no. 11, pp. 2028-2033, 2004.

[43] J. M. Alvarez-Suarez, F. Giampieri, A. M. González-Paramás et al., "Phenolics from monofloral honeys protect human erythrocyte membranes against oxidative damage," Food and Chemical Toxicology, vol. 50, no. 5, pp. 1508-1516, 2012.

[44] D. Steinberg, S. Parthasarathy, T. E. Carew, J. C. Khoo, and J. L. Witztum, "Beyond cholesterol: modifications of low-density lipoprotein that increase its atherogenicity," The New England Journal of Medicine, vol. 320, no. 14, pp. 915-924, 1989.

[45] S. Jamuna, M. Sakeena Sadullah, R. Ashokkumar, G. Shanmuganathan, S. S. Mozhi, and S. Niranjali Devaraj, "Potential antioxidant and cytoprotective effects of essential oil extracted from Cymbopogon citratus on OxLDL and H2O2 LDL induced Human Peripheral Blood Mononuclear Cells (PBMC)," Food Science and Human Wellness, vol. 6, no. 2, pp. 60-69, 2017.

[46] G.-C. Ma, P.-F. Wu, H.-C. Tseng, C.-C. Chyau, H.-C. Lu, and F.P. Chou, "Inhibitory effect of Piper betel leaf extracts on coppermediated LDL oxidation and oxLDL-induced lipid accumulation via inducing reverse cholesterol transport in macrophages," Food Chemistry, vol. 141, no. 4, pp. 3703-3713, 2013.

[47] S. Egert, A. Bosy-Westphal, J. Seiberl et al., "Quercetin reduces systolic blood pressure and plasma oxidised low-density lipoprotein concentrations in overweight subjects with a high-cardiovascular disease risk phenotype: a double-blinded, placebocontrolled cross-over study," British Journal of Nutrition, vol. 102, no. 7, pp. 1065-1074, 2009.

[48] K.-H. Lee, E. Park, H.-J. Lee et al., "Effects of daily quercetinrich supplementation on cardiometabolic risks in male smokers," Nutrition Research and Practice, vol. 5, no. 1, pp. 28-33, 2011.

[49] M. G. L. Hertog, E. J. M. Feskens, P. C. H. Hollman, M. B. Katan, and D. Kromhout, "Dietary antioxidant flavonoids and risk of coronary heart disease: the Zutphen Elderly Study," The Lancet, vol. 342, no. 8878, pp. 1007-1011, 1993.

[50] M.-H. Hoang, Y. Jia, B. Mok, H.-J. Jun, K.-Y. Hwang, and S.-J. Lee, "Kaempferol ameliorates symptoms of metabolic syndrome by regulating activities of liver X receptor- $\beta$," The Journal of Nutritional Biochemistry, vol. 26, no. 8, pp. 868-875, 2015.

[51] E. Ruiz, E. Padilla, S. Redondo, A. Gordillo-Moscoso, and T. Tejerina, "Kaempferol inhibits apoptosis in vascular smooth muscle induced by a component of oxidized LDL," European Journal of Pharmacology, vol. 529, no. 1, pp. 79-83, 2006.

[52] J.-H. Choi, S.-E. Park, S.-J. Kim, and S. Kim, "Kaempferol inhibits thrombosis and platelet activation," Biochimie, vol. 115, pp. 177-186, 2015. 


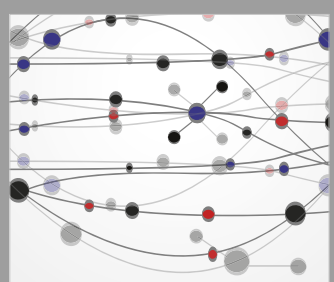

The Scientific World Journal
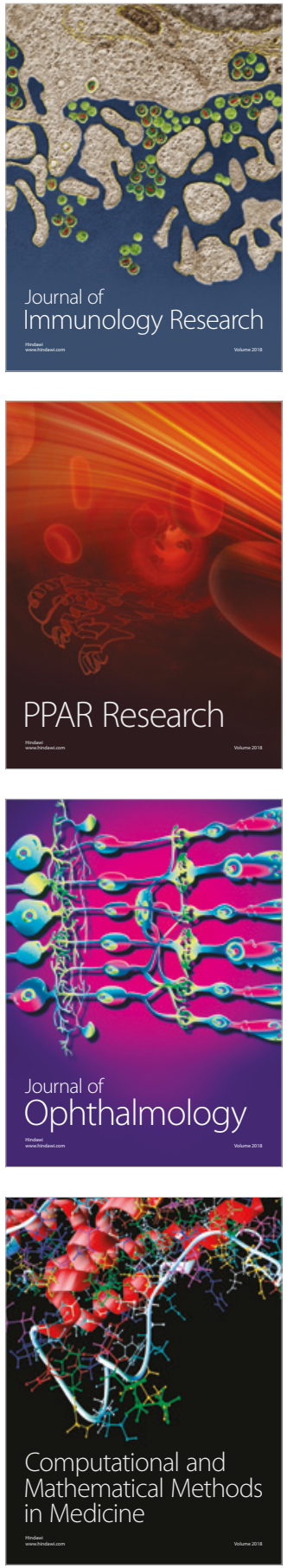

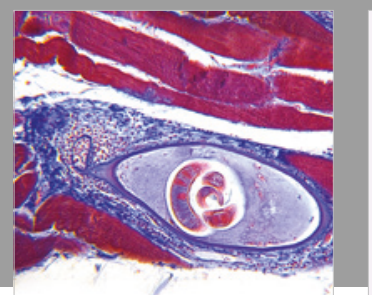

Gastroenterology Research and Practice

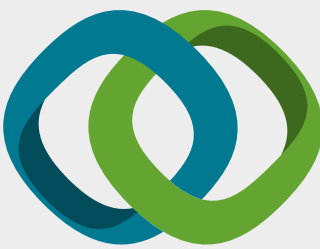

\section{Hindawi}

Submit your manuscripts at

www.hindawi.com
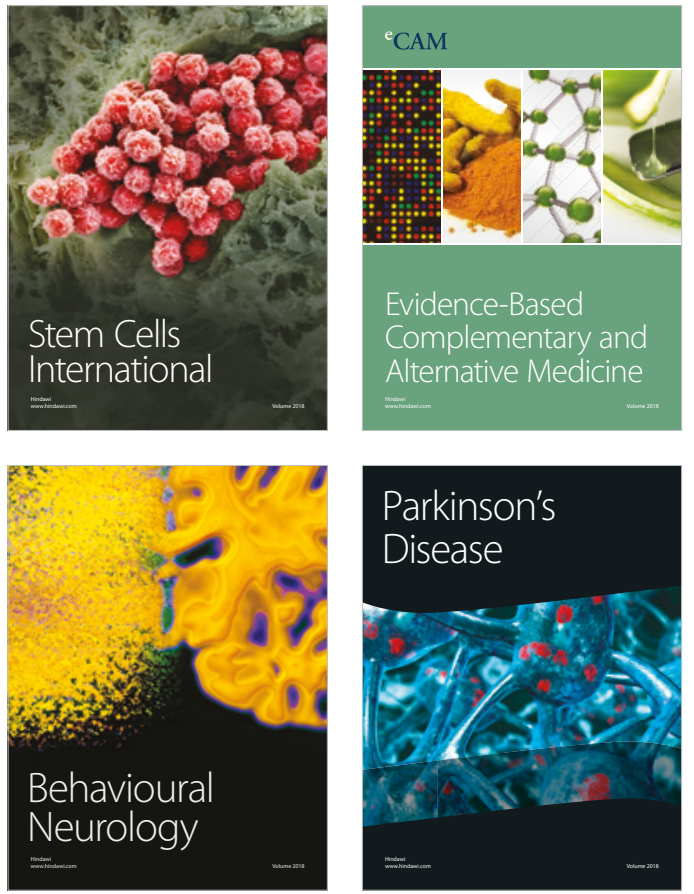

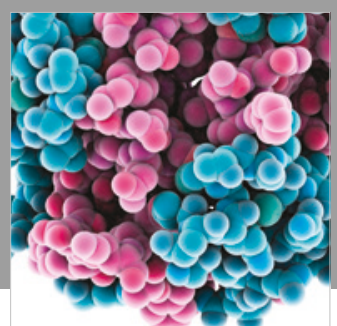

ournal of

Diabetes Research

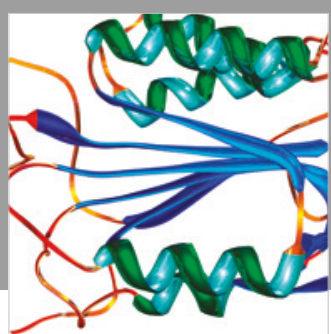

Disease Markers
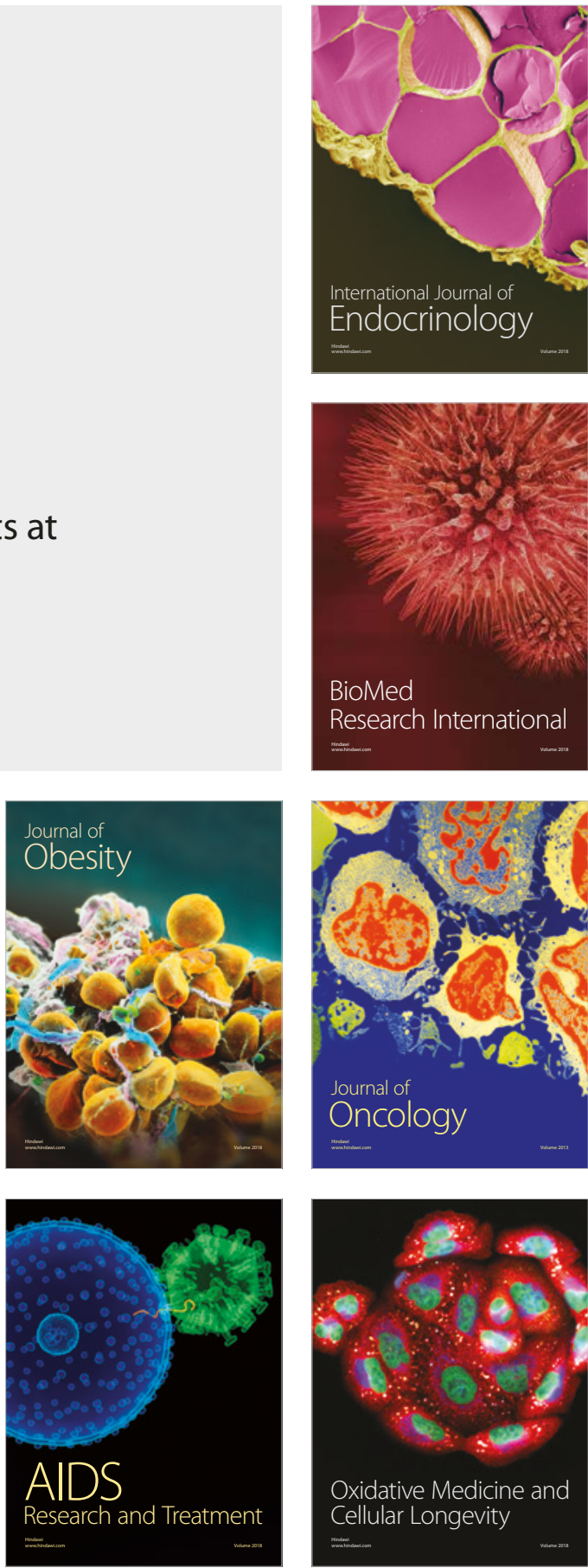